EMBRYARIDDLE
Aeronautical University

SCHOLARLY COMMONS

\section{International Journal of Aviation,} Aeronautics, and Aerospace

\title{
3D TEXTILE PREFORMS AND COMPOSITES FOR AIRCRAFT STRCUTURES: A REVIEW
}

\author{
Abbasali Saboktakin \\ University of sistan and baluchestan, Zahedan, Iran, alaptakin@gmail.com
}

Follow this and additional works at: https://commons.erau.edu/ijaaa

Part of the Manufacturing Commons, Structural Materials Commons, and the Structures and Materials Commons

\section{Scholarly Commons Citation}

Saboktakin, A. (2019). 3D TEXTILE PREFORMS AND COMPOSITES FOR AIRCRAFT STRCUTURES: A REVIEW. International Journal of Aviation, Aeronautics, and Aerospace, 6(1). https://doi.org/10.15394/ ijaaa.2019.1299

This Literature Review is brought to you for free and open access by the Journals at Scholarly Commons. It has been accepted for inclusion in International Journal of Aviation, Aeronautics, and Aerospace by an authorized administrator of Scholarly Commons. For more information, please contact commons@erau.edu. 


\section{Introduction}

Composite materials have been successfully used for structural applications, due to their structural advantages for high specific strength and stiffness. The first generation of composite is 2D laminates. Although these types of composites are characterized by high stiffness and strength properties, they suffer from weak out-of-plane properties, and a more time-consuming fabric layup process. Over the last decades, three-dimensional (3D) textile structures have been developed to overcome those disadvantages of 2D laminates. The development of 3D textile composites has been driven by the needs of reducing fabrication cost, increasing through-thickness mechanical properties, and improving impact damage tolerance. The development of 3D textile composites has been undertaken largely by NASA. Furthermore, the marine, construction, and automotive industries have supported the developments of 3D composites. 3D textile composites containing three-dimensional textile preforms has the following characteristics: improved stiffness and strength in the thickness direction, elimination of the interlaminar surfaces due to integrated structure, possibilities of near-net-shape design, and manufacturing. 3D Textile composites based on textile preforms are manufactured by several textile processing techniques, resin infiltration, and consolidation techniques. Preforms are classified into two main categories called two and three-dimensional textile preforms (Poe, 1997). Dividing 2D and 3D are determined by the presence of reinforcing fibers laying in the through thickness direction as shown in Figure 1. 3D textile preforms can be divided into four major groups according to their manufacturing techniques: Braiding, Weaving, Stitching, and Knitting (Mouritz, 1997). 


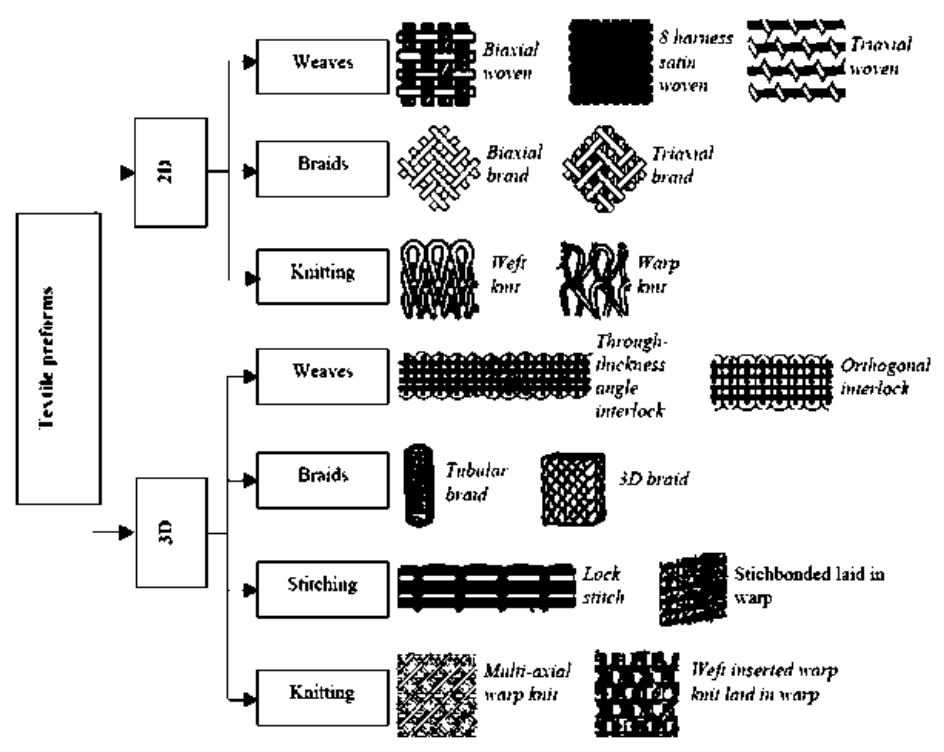

Figure 1. The main category of textiles performs. Adapted from "Handbook of Technical Textiles," by A. R. Horrocks, 2000, Cambridge, England: Woodhead.

In textile composite structures, failures originate from manufacturing defects or in service-induced damage. Manufacturing defect can degrade the performance of textile composite to a point where the composite cannot be used safely for an aircraft structure. The point at which the severity of the defect becomes safety-critical depends on the application and can only be determined by structural integrity assessment. This paper reviews all the processes to produce 3D preforms, fabric architects, and their specification and deformation modes. Textiles stitched preforms and their crucial challenges in order to serve this technique for the future research are discussed. Preform compaction, the effect of compaction, and deformation modes on porosity and permeability are reviewed. Finally, the paper discusses the structural integrity assessment of textile composite by the inspection procedures to prevent structural failure from the manufacturing damages.

\section{Textile Techniques}

\section{Weaving}

As shown in Figure 2, the weaving process involves the insertion of nominally straight weft yarns between layers of warp. The warps lie parallel to the direction of the weaving process designated the $\mathrm{x}$-axis. The weft yarns are oriented orthogonally to the warp yarns, and parallel to the y-axis. Except for a 
little out-of-plane waviness, the warp and weft yarns lie purely in the x-y plane without interlacing each-other similarly to a $0 / 90$ laminate. In $3 \mathrm{D}$ weaving, a small proportion of in-plane yarns are woven that they bind together the multiple layers of warp and weft yarns. These yarns are termed ' $z$ binders'; because they are woven through the thickness of the preform, designated the z-axis. 3D woven preforms can be manufactured by using the most common types of commercial weaving looms. Jacquard looms are the most popular due to their high degrees of automation and good control of the fiber structures. The benefits of this automation in weaving process are: reducing the manufacturing costs versus reducing the labor hours, scrap rates, process inspections, and consequently, increasing repeatability and quality control. The loom can be used to manufacture integrated, net-shape preforms such as blade stiffened panels.

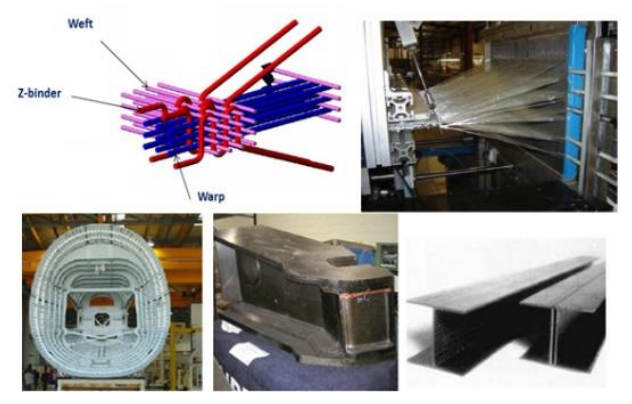

Figure 2. 3D-weaving machine and 3D woven composite applications. From left to right: Fuselage, Landing gear, 3D woven I-beams. Adapted from "Review of Applications for Advanced Three-Dimensional Fibre Textile Composites," by A. Mouritz, 1997, Compsoite, 30(12), p. 1445- 1461 and "Introduction," by J. Hearle, 2015, Advances in 3D Textiles. Cambridge, England: Woodhead.

\section{Stitching}

There has been considerable interest in composites produced by stitching layers of textile fabric and subsequently impregnating the preform with resin by using a liquid molding technique. The stitching process is carried out using industrial stitching machines. Stitching machines can stitch various kinds of preforms with high performance yarns as stitching threads. The extent of throughthickness reinforcement in stitched composites structures is between 1 to 5\%, which is a same amount of reinforcement in 3D woven, braided and knitted composites (Bogdanovich \& Mohamed, 2009; Tong, Mouritz, \& Bannist, 2002). The use of through-thickness stitching in composite owes to the following reasons: possibility to joining composite structures to provide high throughthickness strength and resistance to peel loads, decreasing the costs of component 
manufacture greatly by reducing RTM tooling costs, improving interlaminar fracture toughness, impact resistance and tolerance, construct 3D complex shapes by stitching several separate preforms together, eliminating the need for mechanical fasteners, such as rivets, screws and bolts, and finally, reducing the weight and production cost as well. Figure 3 depicts the manufacturing stage of an aircraft composite panel stiffened by stitching process.

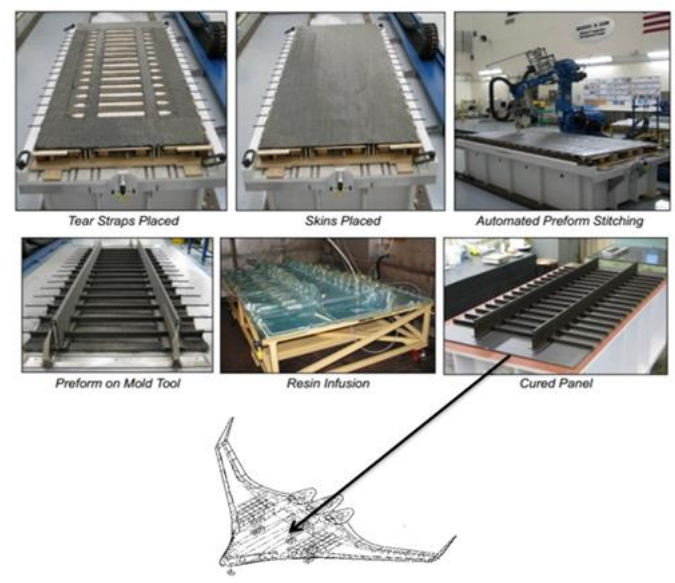

Figure 3. Manufacturing process of stiffened stitched panel using vacuum infusion process and its location on the BWB aircraft. Adapted from "Approach to Net-Shape Preforming Using Textile Technologies," by C. Weimer, P. Mitschang, and K. Drechsler, 2000, Composites: Part A, 31(11), p. 1261-1268.

Despite these advantages for stitched composites, there are some disadvantages with the stitching process. The main one of those is a reduction in the in-plane properties of the resultant composite component. As the needle penetrates into the fabrics, it can cause localized in-plane fiber damages and fabric distortions, which have been found to reduce the mechanical performance of the composites. Furthermore, the performance reduction is increased by the loops formed during stitching which can also crimp the fabric in the thickness direction if the tension in the stitch thread becomes high. Stitching process causes distortions in the fabric and in resin rich regions in the composite. This region mostly acts as a crack initiator which can decrease the performance of composite. More details on damages caused during stitching can be found in the next section. 


\section{Stitching types.}

The type of the stitching method used in composite is a significant factor. Lock stitch is one of the most common types of stitching techniques. Mostly, this stitch has been applied for the cloth industry. It is composed mainly of a two loop between the needle and the bobbin (see Figure 4a). The lock stitch needs access to both top and bottom of the textile fabric. This type of stitching is not appropriate for composites because the thread intersection in the middle of the fabrics causes a stress concentration. Therefore, modified lock stitch shown in Figure $4 \mathrm{~b}$ is typically used in composite industry that allows the needle thread to move on the composite surface instead of the middle of composite. Moreover, a chain stitch method shown in figure $4 \mathrm{c}$ is used in composite industry. This method has similar mechanism to the lock stitch. Other sewing machines can generate two types of stitches; tufting and dual-needle stitching (see Figure 4d).

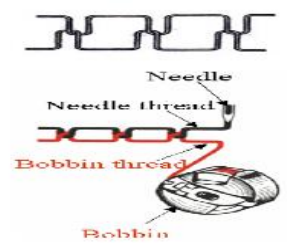

a)

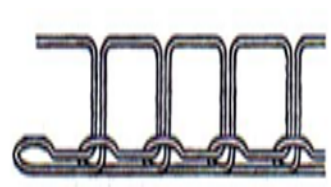

c)

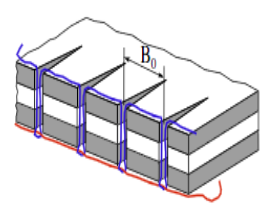

b)

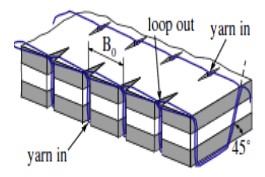

d)

Figure 4. Stitching Types (a) Lock stitch; (b) Modified Lock stitch; c) Chain stitch; d) Dual lock stitch. Adapted from "Handbook of Technical Textiles," by A. R. Horrocks, 2000, Cambridge, England: Woodhead.

In addition to stitching techniques including lock stitch and chain stitch which need access to both sides of the fabric there is other techniques that need only one side of fabrics (see Figure 5). In these techniques, a curved needle or hooked needle have been used. The maximum thickness of preform to be stitched using these techniques is around $20 \mathrm{~mm}$. 


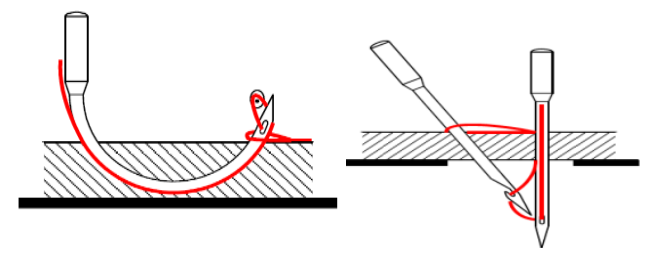

Figure 5. Different type of blind stitch technique developed for composite industry. Adapted from "Aeronautics Research," n.d. and "Handbuch Verbundwerkstoffe" by M. Neitzel, 2004, Munich, Germany: Nanzer.

\section{Stitching parameters.}

The significance of stitching parameters to produce high quality composite becomes obvious during the preform impregnation by resin. Large number of variables in stitching techniques have been reported while there are many interactions among these variables. The major parameters of stitching process are as follow: stitching pattern, stitch density, and thread type and diameter as well as manufacturing variables including thread tension, foot pressure, needle type/size, textile fabric, and machine type. These parameters have significant effect on strain distribution and concentration in 3D composite structure ("Cyber and Digital Resilience," n.d.). To be clearer, Figure 6 depicts compaction curves for stitched panels with varied thread tension. In the preform stitched with high thread tension $(550 \mathrm{cN})$ there is yarn bending, nesting, and yarn cross-section deformation and it requires a high force for compaction of such textile perform.

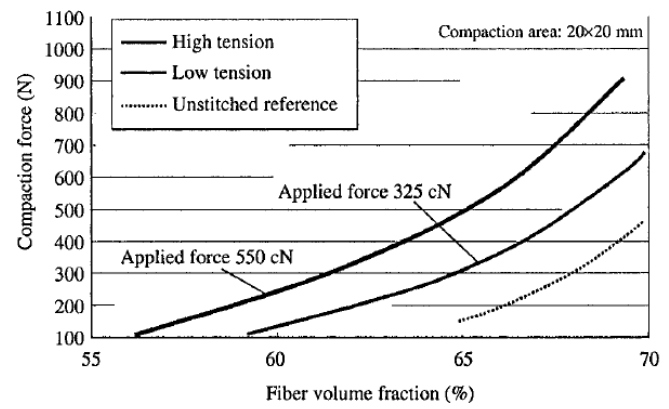

Figure 6. Influence of thread tension compaction force for a stitched woven preform. Adapted from “Cyber and Digital Resilience," n.d.

Needle characteristic is other significant parameters should be taking into account to have high quality stitched preform. The needle size dominates the amount of the spreading of the fiber during the penetration process such that it can be said the expansion of needle holes is strongly function of needle size. Figure 7 demonstrates the influence of two different size of needle diameter on formation of resin rich region. Deflection of needle size highly depends on the material 
thickness. To know effect of these parameters many tests with the proper consideration of several variables have to be done. Therefore, experimental design techniques paly major role for these types of reinforced preforms.

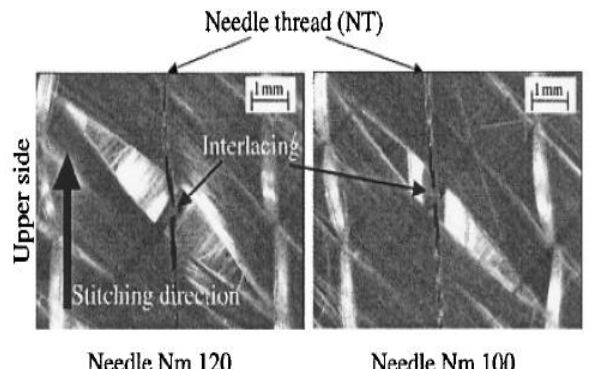

Figure 7. Effect of needle diameter size on rein rich region occurred during stitching. Adapted from "Tailoring of Textile Preforms for Fibre Reinforced Polymer," by A. Ogale and P. Mitschang, 2004, Composites, 34(2), pp. 77-96.

Stitching thread is another main parameter should be considered during the stitching preforms. Figure 8 represents the selection of stitching thread type based on stitch type and preform characteristics, application areas and desired mechanical properties.

\begin{tabular}{|c|c|c|}
\hline Stitch type & Seam type & Thread applicable \\
\hline \multirow{3}{*}{ Modified lock stitch } & Fixing and positioning & Thin, flexible, high elongation polyester \\
\hline & Assembling & Thicker polyester, Nomex ${ }^{\circledast}$, or Kevlar ${ }^{\otimes}$ \\
\hline & Structural (3-D) & Carbon, glass, Kevlar $^{\circledast 2}$ \\
\hline \multirow{2}{*}{ Chain stitch } & Fixing and positioning & Medium thick, less elongation polyester \\
\hline & \begin{tabular}{|l} 
Assembling \\
\end{tabular} & Thick, less elongation polyester, Kevlar \\
\hline \multirow{2}{*}{ One-sided stitch } & Assembling & Thick polyester \\
\hline & Structural (3-D) & Carbon, glass, Kevlar \\
\hline \multirow{2}{*}{ Blind } & Fixing and positioning & Medium thick polyester \\
\hline & \begin{tabular}{|l} 
Assembling \\
\end{tabular} & Polyester, Nomex ${ }^{\infty}$, or Kevlar \\
\hline \multirow{2}{*}{ Tufting } & Assembling & Polyester, Kevlar ${ }^{\circledast}$, glass \\
\hline & Structural(3-D) & Carbon, glass, Kevlar ${ }^{\circledR}$ \\
\hline
\end{tabular}

Figure 8. Selectivity of stitching thread based on the stitch type and preform application. Adapted from "Knowledge Center," by Bissell, n.d.

Tailored fibre placement.

Technical embroidery or tailored fibre placement (TFP) mostly has been used to provide in-plane reinforcement accompanied with through-thickness reinforcement. In this stitching technique shown in Figure 9, a reinforcement thread is fed into the stitching path and is stitched onto the preform surface in zigzag pattern while machine automatically moves the material corresponding to the pattern defined by software developed for TFP.

Recently, CNC machines facilitated the placing the reinforcement thread in complex path to meet maximum stress distribution in desired direction. High level of automation in $\mathrm{CNC}$ machine make able to produce complex shaped 
preforms with considerable cost saving.
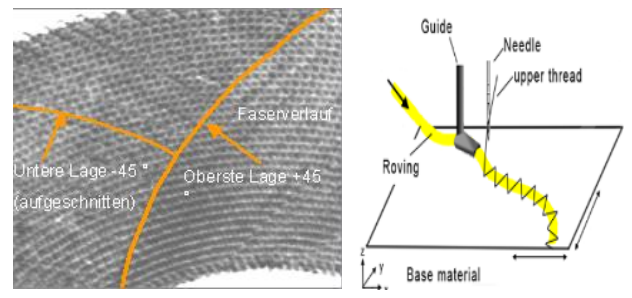

Figure 9. Example preform produced by tailored fibre placement and schematic of embroidery machine. Adapted from "Polymer-Composites: From Nano- to Macro-Scale," by K. F. Friedrich, K. Fakriov, and Z. Zhong, 2005, New York, NY: Springer.

\section{Tufting.}

As shown in Figure 10a, tufting is a one-sided stitching technique in which the formation of loops is done by a tension-free of stitching thread. Figure $10 \mathrm{~b}$ indicates the top-side and underside of a tufted preform along with tufting machine. In this technique, the bonding between the matrix and stitching thread is created only after resin injection. However, significant fibre damages created in tufting reduce in-plane strength of final composite parts. Based on literature review the knitted fabrics are inappropriate for use with this technique whilst woven fabrics are somewhat easy to tuft due to their interlaced architects. Furthermore, non-crimped-fibre (NCF) fabrics seem appropriate for tufting process.

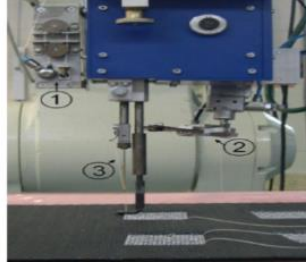

a)

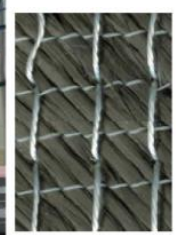

b)

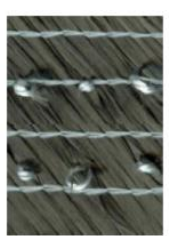

Figure 10. Tufting machine and a schematic of tufting stitch. Adapted from "Quality Aspects of and Thread Selection for Stitched Preforms," by P. Mitschang and A. Ogale, 2009.

\section{Applications of stitched preforms.}

Many research projects have been carried out to evaluate the applicability of stitched textile preforms for aerospace structures. For instance, NASA in cooperation with Boeing has developed a 28 -meter long stitching machine with 
the aim to manufacture aircraft wing components by a reduction of about $25 \%$ in weight and $20 \%$ in costs compared with equivalent aluminum parts (See Figure 11a). Recently, Airbus Company and its collaborators have moved to use stitching technique for the manufacture of primary structure of aircraft such as passenger door of commercial aircrafts (see Figure 11b).

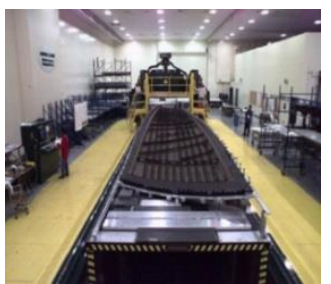

a)

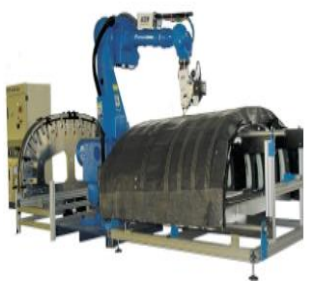

b)

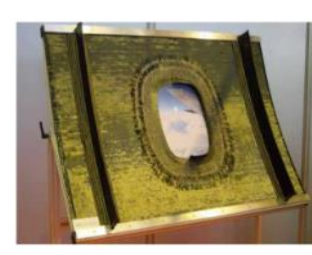

c)

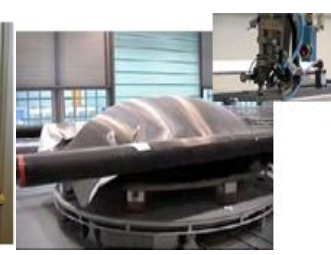

d)

Figure 11. Production of complex shape preform using stitching techniques. Adapted from "Design," by Robo-technology.com, n.d.; "Informacion," by Interempresas.net, n.d.; and "Robotic Approach to Textile Preforming for Composites," by A. Potluri, T. Sharif, and D. Jetavat, 2008, Indian Journal of Fibre \& Textile Research, 31, pp. 333-338.

Other examples for stitched preform is shown in Figure 11. Furthermore, the stitching technique has been developed to produce a CFRP stator. These developments of stitching techniques seem a promising even for the automotive industry to benefit of the tremendous weight reduction and specific mechanical properties in particular to increase crash performance. 


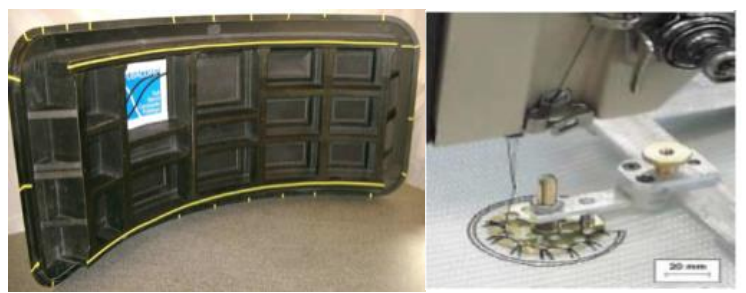

Figure 12. a) Production of aircraft door using stitching process; b) Replacing welding and jointing bolt with stitching process. Adapted from "Aeronautics Research," n.d.

Furthermore, stitching process can be used to connect the mechanical part rather than welding and bolting. These methods make able to transfer the stress received by composite to metal parts and also decrease the manufacturing difficulties.

Lately, 3D stitching robots have been employed to make the textile preforms in the shape of a desired component. The robot can stitch the net-shape preform to improve the strength and weight to meet the end application requirements and also decrease handling and lay-up time (Poe, 1997). Furthermore, the robotic stitching head enables to arrange the 3D dimensional motion to produce very complex shaped preform.

Although the stitching technique using robot has been reliable in its performance, the development of appropriate fixation devices for the production of textile preform using robot is main challenge. Figure $12 \mathrm{~b}$ indicates a typical fixture for the production of a curved preform for fuselage sectors.

\section{Braiding and Knitting}

3D braiding process can be used for producing a near net-shape preforms. This process can be applied to produce airframe spars, F-section fuselage frames, rib stiffened panels, rocket nose cones, fuselage barrels, tail shafts, and rocket engine nozzles. In braiding process, several carriers move spools in the circular path such that the end of yarns is fixed on a mandrel and interlace. The main disadvantages of the 3D braiding process, shown in Figure 13, are slow throughput and complicated setups.
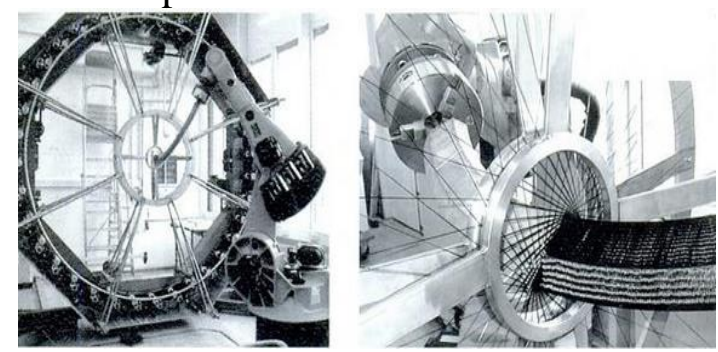

Figure 13. Robotic braiding of a J-stiffener. Adapted from "Aeronautics Research," n.d. 
Knitting process is used to the production of garments. It has received attention from preform manufacturers for producing complex 3D structures. The knitted fiber architecture results high flexibility, however the major disadvantages of this process is fiber breakages occurred during the manufacturing of preform in particular for carbon fibers. Other major problem around the knitted reinforcements is the loop structure makes local stress concentrations, so their mechanical properties are generally lower than alternative techniques. See Figure 14.

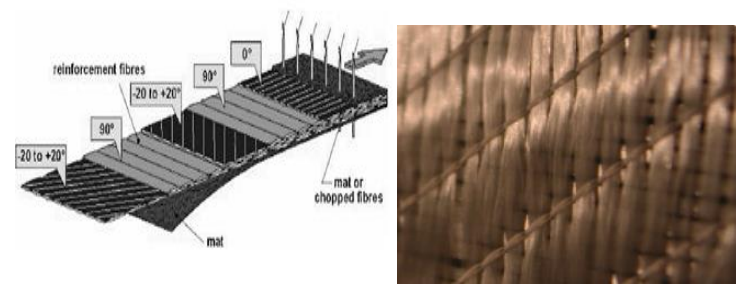

Figure 14. Manufacture of multiaxial warp knitted fabric by LIBA technique and snapshot of knitted fabric (courtesy of LIBA).

\section{Fabrics Deformation Modes}

The use of textile fabrics in aerospace industry gives the possibility to produce complex shapes components using liquid composite moulding. The textile fabric structure influences the manufacturing properties such as deformability, porosity and permeability and mechanical properties of final composite parts. The characterisation of local fiber variation occurred during forming, fiber volume fraction and fiber thickness are significant parameters to describe the performance of textile fabrics. During the forming of textile fabrics, the following deformation mode occur: shearing, straightening, wrinkling, stretching, inter-ply slipping and intera-ply slippage. If the directions of applied tensile load to textile fabric do not coincide with the fibre tow orientation, fabric shear mode occurs. This deformation mode is subject to high friction in the crossing points depicted in Figure 4a. Figures $15 \mathrm{~b}$ and $15 \mathrm{c}$ depict the shearing modes occurred in transverse or parallel to fiber tow. 


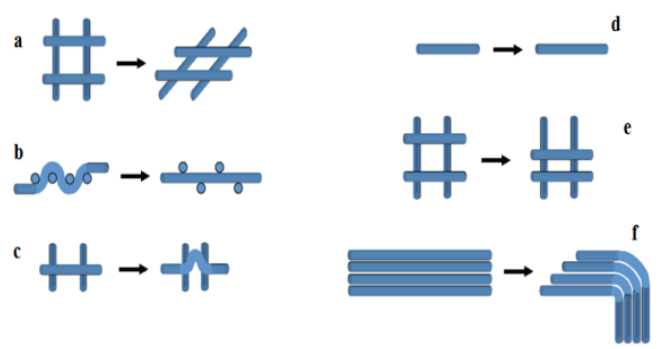

Figure 15. Deformation modes of textile fabric a) shearing; b) straightening; c) wrinkling; d) stretching; e) intra-ply slippage; f) inter ply slippage. Adapted from "Integrated, Optimized Aircraft Door - High Performance Composites," by Gardner Business, n.d.

Fibre straightening is accompanied with changes in fibres curvature under tensile load. Effect of Fibre straightening mode is substantial for knitted fabrics, however effect is low for other fabrics with low-undulation structure. Elastic stretching of fiber has minor importance, because the reinforcement textiles used for advanced applications are composed of high elastic tensile modulus. Interplay and intra-ply slipping of the fibre tows mostly occur at corners of the surface and sharp edges.

In addition to the deformation modes mentioned above, other effects such as bending and torsion shown in Figure 16.d occur. It can be because of friction between the fibre tows and compression caused by forces normal to the axes of the fibre tows.

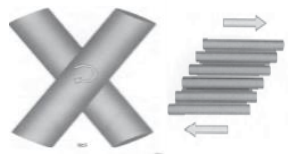

a)

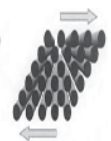

b)

Figure 16. a) fiber shearing in direction of fiber tow and in transverse direction; b) Bending and twisting deformations. Adapted from "Textile Halbzeuge," by P. Ermanni, 2009.

\section{Identification of mechanical properties of textile fabrics.}

Based on the deformation modes demonstrated above, textile mechanics of performs must include a description of their behaviour under combined biaxial tension, shear and compression loading conditions. To be clearer, a summary of these tests as well as fabric behavior under loading are explained as follow. 


\section{Tensile test.}

Uniaxial test under specified load causes a reduced tow undulation in the loading direction and an increased tow undulation in the transverse direction. The information acquired during uniaxial tensile test is highly significant for knitted fabric due to their high module.

\section{Shear test.}

Shear test is used to measure the shear properties of textile fabric using two different test methods: pure shear and bias extension (see Figure 17). In bias test, the direction of two fibers are perpendicular to each other at $\pm 45^{\circ}$ (bias direction). As shown in Figure 17b, three different zones occur in bias test. In zone I, the warp and weft yarns have clamped at one end and no deformation is observed in this zone.

In zone II, the fibre tow orientations alter until the fibre axes coincide with the directions of the applied load or until locking angle (maximum shear angle) of fiber is achieved. Locking angles of woven fabrics are in the range between $15^{\circ}$ and $40^{\circ}$ depending on the woven fabric architecture. It should mentioned that the wrinkling defect initiate in this zone due to high local shear stresses. In zone III, one tow direction is clamped and stretching of the fabric results a shear strain that is about half of that of the zone II.

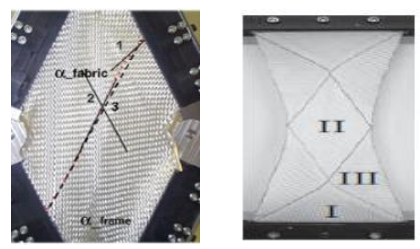

a)

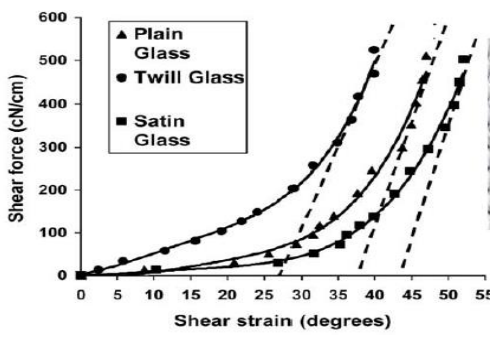

b)

Figure 17. a) picture frame test and Bias test of textile fabric indicates three different zones; b) shear force vs. strain for different textile structures. Adapted from "Design and Manufacture of Textile Composites," by A. C. Long, 2009, Boca Raton, FL: CRC. 


\section{Compression test.}

The compression test is used to measure the fabric thickness subjected to an increased pressure. Compression load applied to fabric results an increase in fibre volume fractions by tow flattening and decrease in tow crimp (see Figure 18). It should be noted that, in reality, the applied force to fabric is divided to small force on contact points of yarn, however average pressure is used to express the force applied to all surface of textile including yarn and gap between yarns.

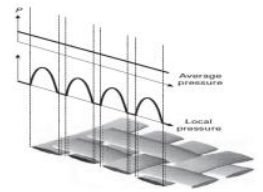

a)

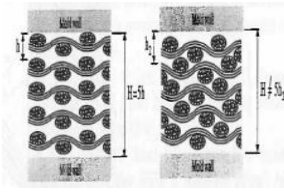

b)

Figure 18. a) Comparison of average and local pressure in compression of fabric; b) stacking of textile with and without aligment in inplane direction. Adapted from "Textile Halbzeuge," by P. Ermanni, 2009, and "Full-Field Strain Measurements in Textile Deformability Studies," by S. Lomov, P. Boisse, E. Deluycker, and F. Moresten, 2008, Composites Part A: Applied Science And Manufacturing, 39(8), pp. 1232-1244.

Textile fiber compressibility highly depends to nesting of fiber during the stacking of several textile layers. For instance, high fiber volume fraction occurs with a decrease of the preform thickness with increasing number of textile layers in the case of max nesting as shown in Figure 19a. Figure 19b depicts a typical pressure-thickness curve of woven fabrics. The curve is composed of three parts: tow linear parts an exponential part. Linear parts are related to preform compactions because of the decrease of porosity and gaps among the fibers and yarns, whereas the exponential part is related to yarn bending, nesting and yarn cross-section deformation. 


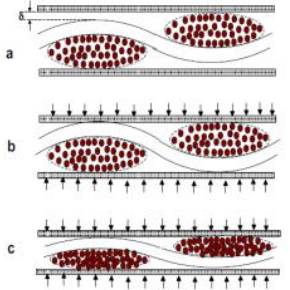

a)

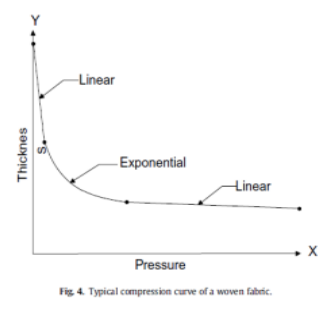

b)

Figure 19. a) Schematic of compression mechanic of woven fabric; b) Thickness vs. compression pressure curve of woven fabric. Adapted from "Characterization and Prediction of Compaction Force and Preform Permeability of Woven Fabrics During the Resin Transfer Molding Process,” by E. M. Sozer, B. Chen, P. J. Graham, T. W. Chou, and S. G. Advani, 1999, and "Compaction of Woven-Fabric Preforms: Nesting and Multi-Layer Deformation, by C. Baoxing and C. Tsu-Wei, 2000, Composites Science And Technology, 60(12), pp. 2223-2231.

\section{Bending test.}

This test determines bending stiffness is significant for the preform forming process. A typical non-linear bending moment as function of curvature relation is depicted in figure $20 \mathrm{~b}$. It should be noted that out of plan bending effect can be ignored for 2D preform, however it cannot be neglected for 3D preform due to tow change. See Figure 20. 


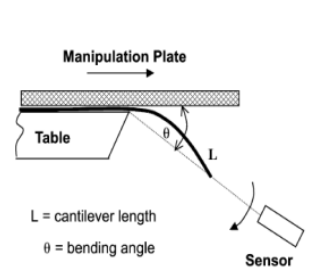

a)

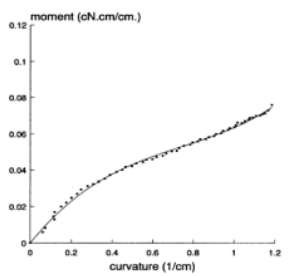

b)

Figure 20. a) Snapshot of in-plane bending test; b) moment curvature curve recorded for woven fabric. Adapted from "Compaction Modelling of Textile Preforms for Composite Structures," by P. Potluri and T. V. Sagar, 2008, Composite Structures, 86(1-3), pp.177-185.

\section{Friction test.}

Frictional force between a tool surface and fabric, or inter-ply shearing is measured by friction test. Figure 21 represents the friction coefficient versus displacement obtained for a textile fabric.

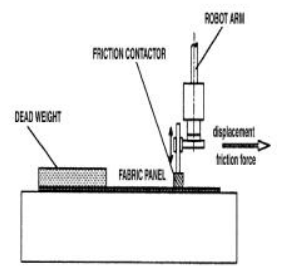

a)

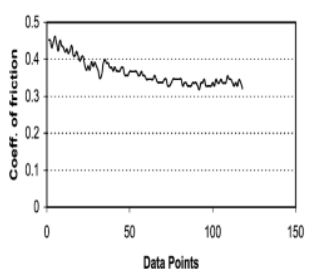

b)

Figure 21. a) schematic images of friction test; b) example displacementCoefficient of friction curve of textile fabric. Adapted from "Compaction Modelling of Textile Preforms for Composite Structures," by P. Potluri and T. V. Sagar, 2008, Composite Structures, 86(1-3), pp.177-185.

\section{Textile Forming}

Complex shaped textile composite needs the formation of textile fabric in tools before resin injection. The draping of textile fabrics on double curved surfaces has received much attention both in 2D and 3D textile structure for description of the textile behaviour for forming. For instance, drapability of fabric for a nose cone or blade geometries are the main characteristics have been investigated for the adaptation of fabric on their tools (Otluri \& Atkinson, 2003). See Figure 22. 

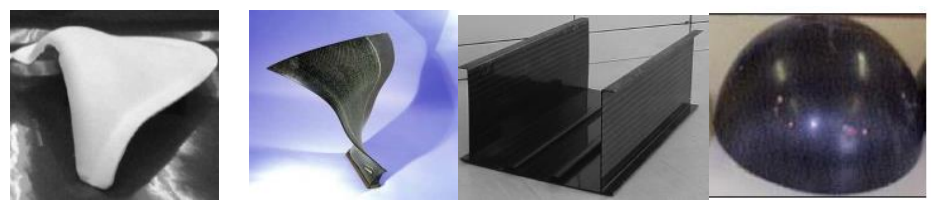

Figure 22. Typical complex shape parts composed of textile fabric. Adapted from "Review of Applications for Advanced Three-Dimensional Fibre Textile Composites," by A. Mouritz, 1997, Compsoite, 30(12), pp.1445-1461; “3D Woven Near-Net-Shape Preforms for Composite Structures," by A. Mountasir, M. Löser, G, Hoffmann, C. Cherif, and K. Großmann, 2016, Advanced Engineering Materials, 18(3), pp. 391-396; and "Prediction of Fiber Orientation and Microstructure of Woven Fabric Composites After Forming," by Y. Baillargeon and T. Vu-Khanh, 2001, Composite Structures, 52(3-4), pp. 475-481.

The drapability of textile fabrics can be expressed in terms of shear deformation, local shear angle yarn slippage and wrinkling defect. To be clearer, drape test of four different types of textile fabric including a basket, plain, twill, and satin weave are depicted in Figure 23.

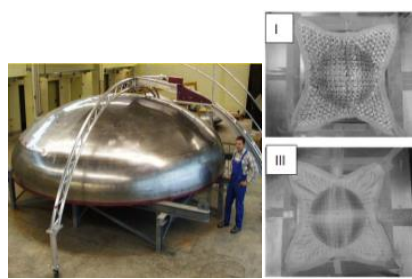

a)

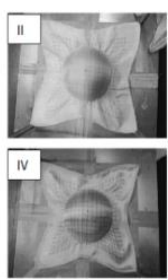

b)

Figure 23. a) double curve surface used for manufacturing of bulkhead pressure; b) textile fabrics draped on hemispherical I) Basket II) Plain III) Twill IV) 5harness Satin. Adapted from "Characterization and Prediction of Compaction Force and Preform Permeability of Woven Fabrics During the Resin Transfer Molding Process," by E. M. Sozer et al., 1999, and "CFRP Using Braided Preforms/RTM Process for Aircraft Applications," by T. Uozumi, A. Kito, and T. Yamamoto, 2005, Advanced Composite Materials, 14(4), pp. 365-383.

It is clearly seen that the plain weave exhibits high shear deformation and the worst drapibility due to high level of fiber undulation in compared with other fabrics. It is worth to say that these local shear deformations can result considerable local change of fiber volume fraction. Figure 24 represents a comparison between several textile woven fabrics based on the deformability and stiffness. 


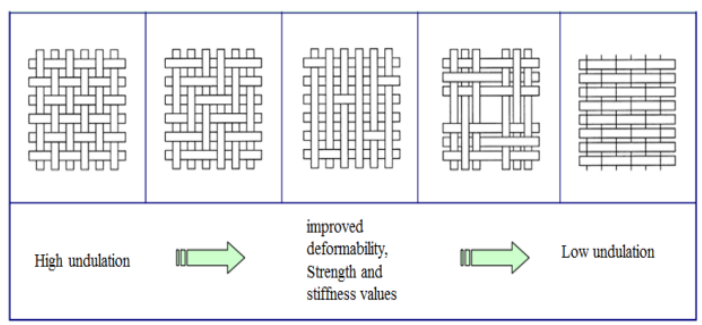

Figure 24. Comparison of different woven architect from aspect of their characteristics. Adapted from "Characterization and Prediction of Compaction Force and Preform Permeability of Woven Fabrics During the Resin Transfer Molding Process," by E. M. Sozer et al., 1999.

\section{Classification of fiber structure}

Characterisation of the textile fabric based on shear stiffness and drapability is needed for accurate prediction of the fabric forming for 3D-complex shaped composite structure. Figure 25 depicts relation between shear stiffness and drapability for different fabrics. It is clearly seen that UD fabric has low drapability and shear stiffness due to lack of undulation. Knitted preforms have high conformability, however lower in shear stiffness due to curved fibers.

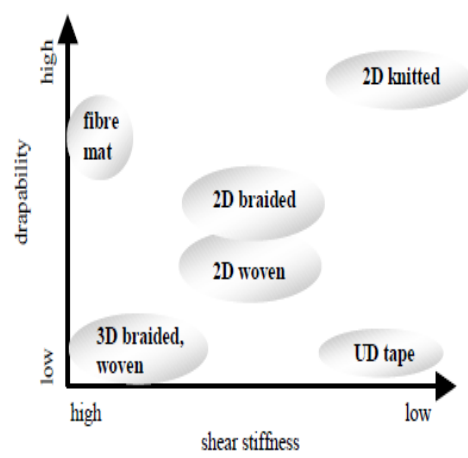

Figure 25. Textile fabric characteristic based on drapability and shear stiffness. Adapted from "Integrated, Optimized Aircraft Door - High Performance Composites," by Gardner Business, n.d.

3D woven has high stability and shear stiffness due to reinforcing fiber in the through thickness direction. Braided fiber in compared with other fabrics has low shear resistance, but relatively high drapability. Based on Figure 25, it can be concluded that braided preform are more suitable for varying cross-sectional shapes such as cones and nozzles (Mountasir et al., 2016). 


\section{Textile Composite Manufacturing process}

A wide range of manufacturing processes are available for the textile composite. The most commonly used process is Resin Transfer Molding (RTM) which provides industry to manufacture net shape parts in closed tooling. The main feature of RTM is the injection of the liquid polymer through a dry preform laid in a closed mold. The impregnation quality depends on the combination of pressure at which the resin is injected, temperature, resin viscosity, mold cavity shape and preform properties (Luycker, 2006). Many other techniques are derived from this manufacturing method, such as the resin infusion process or VARTM in which resin flows through the mold and impregnates the fibers due to vacuum applied in the outlet RTM (see Figure 26). This technique allows the possibility to fabricate various composite components ranging from low to high performance, and small to large dimensions. Highly complex structures can be produced by using of VARTM that reducing part-count and off-setting costs with the intermediate assembly stage.

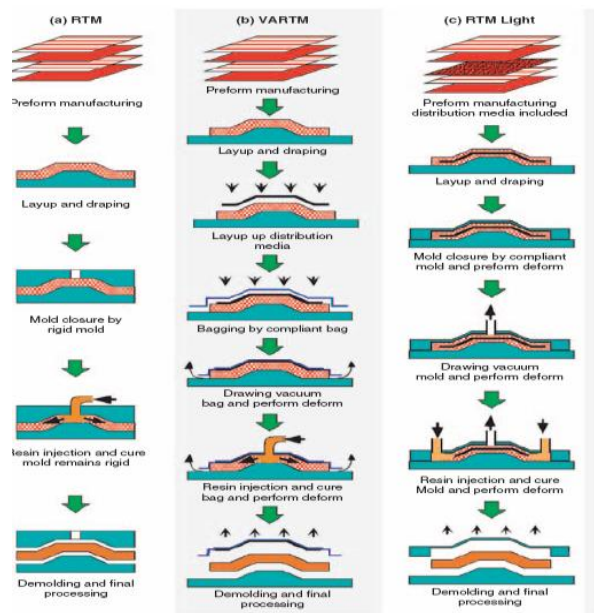

Figure 26. Typical composite manufacturing process. Adapted from "Composites Manufacturing: Materials, Product and Process Engineering," by S. Mazumdar, 2002, Boca Raton, FL: CRC.

\section{Dependency of resin flow to fabric structure.}

Prediction of resin flow to produce high quality composite using RTM and VARTM process requires detailed knowledge of preform permeability and the impregnation behavior of the fiber preform materials under compaction. On the other hand, permeability and flow pattern highly depend on preform structure. Below gives a summary of preform characterisation in terms of thickness, porosity and permeability and their effect on flow pattern. 


\section{Effect of preform thickness on flow patterns.}

The preform thickness is directly related to the fiber volume fraction and the compression applied into the preform during the preforming process. Figure 27 depicts examples 3D preform with different thickness. Preform thickness has high influence on flow fronts and lag formation. As shown in Figure 28, the lag is due to the high permeability on the top surface of the preform. The lag increases with increasing specimen thickness because of the increased volume of resin needed to flow through the thickness and fill greater volume of pores in the preform. To eliminate the lag phenomena, the infusion process needs to continue until the lagging region is completely impregnated with resin.

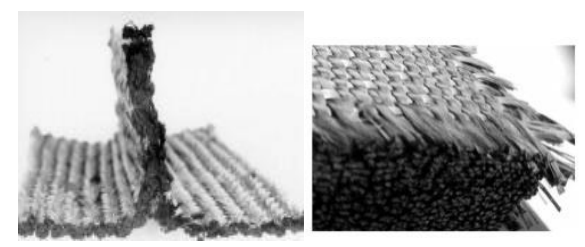

Figure 27. Typical example of thin braided and thick woven(100mm). Adapted from "Three-Dimensional Reinforcements for Composites," by E. Bogdanovich and M. Mohamed, 2009, and "Prediction of Fiber Orientation and Microstructure of Woven Fabric Composites After Forming," by Y. Baillargeon and T. VuKhanh, 2001, Composite Structures, 52(3-4), pp. 475-481.

It should be noted that the flexible vacuum bag in VARTM process and varying pressure inside the mold cavity cause the preform thickness variation and, therefore, the fiber volume fraction of the preform alter during infusion. So to produce high quality composite, the permeability of the preform should be examined at varying fiber volume for different case of the variation of compaction pressure. 


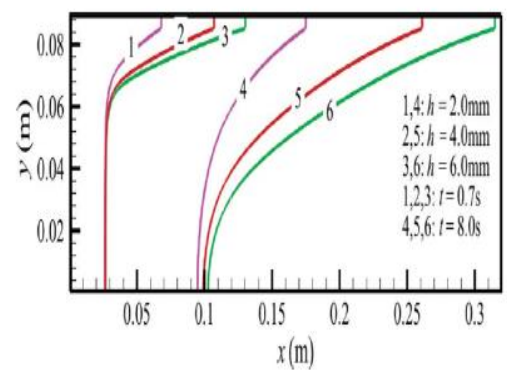

Figure 28. Effect of variant preform thickness on lag formation. Adapted from "Modeling Flow in Compression Resin Transfer Molding for Manufacturing of Complex Lightweight High-Performance Automotive Parts," by P. Simacek, S. G. Advani, and S. A. Iobst, 2008, Journal of Composite Matererails 42(23), pp. 2523-2545.

Injection pressure is influenced by preform architect, preform thickness, and layup sequence of textile fabrics. Occasionally, a small variation in preform thickness can severely influence the injection pressure. For instance, a local reduced thickness in corner the mold may result lower preform permeability and consequently increase molding pressure.

\section{Compressibility of textile fabric}

Two various phenomena are observed during the preform compaction to achieve high fiber volume and lower porosity. First, the response of dry preform under the compaction loading is not elastic, and the hysteresis occurs during unloading process. The hysteresis mainly is due to relaxation behavior of the textile preform occurred during compression and decompression experiment (Grujicic, Chittajallu, \& Walsh, 2005). Second, the wet fiber impregnated with resin is compacted more than the dry preform under the identical compression loading due to the effect of resin lubricant. Therefore, it can be said that before resin impregnation, the dry preform is under vacuum compression and compressive strain of preform is related to only compaction response of dry preform. In this case, the compression strain highly depend fiber elastic properties and friction occurred during slippage mentioned before. After the resin injection, the local pressure applied to the preform drops. It is corresponding to an unloading stage. Figure 29 represents the typical pressure vs. porosity curve recorded for textile fabric. At the first stage, there is homogeneous porosity because fabrics are homogeneously compressed. Following the resin injection, inhomogeneity of resin pressure occurred in flow channel cause inhomogeneous distribution of porosity inside preform. 


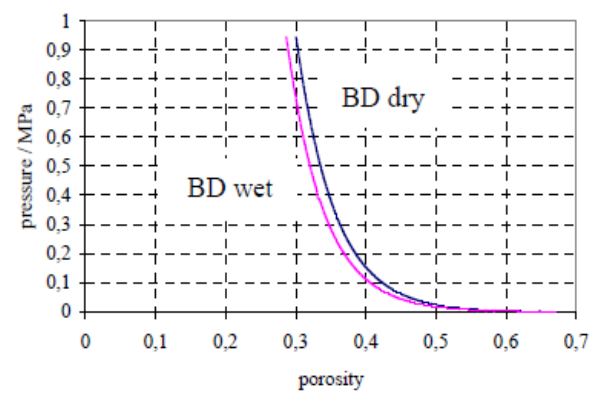

Figure 29. Compression pressure relationship of dry and wet preform. Adapted from "Compaction of Textile Reinforcements for Composites Manufacturing. I: Review of Experimental Results," by F. Robitaille and R. Gauvin, 2014, Polymer Composites, 19(2), 198-216.

\section{Dependence of permeability in textile fabric.}

The quality of the composite parts significantly affects preform permeability that affects the injection process. Inhomogeneities in porosity and fabric geometry occurred during deformation and preform compression severely influence the textile permeability. Figure 30 denotes the relation influence of the fiber volume fraction and porosity on permeability parameter.

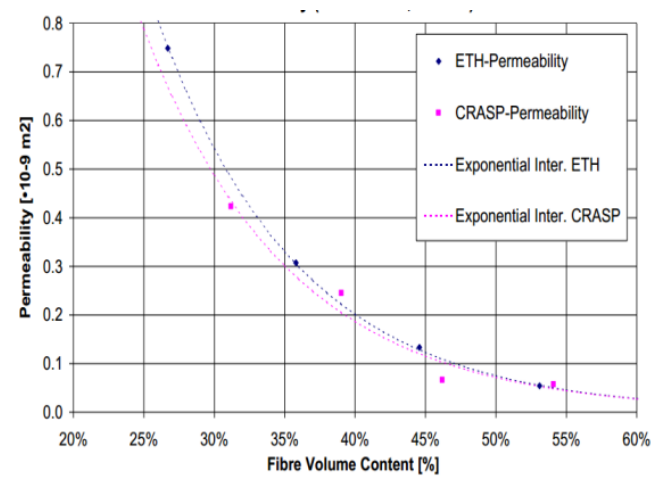

Figure 30. Influence of fiber volume fraction on permeability. Adapted from "Investigation of the Influence of Local Inhomogeneities in the Textile Permeability on the Resin Flow in Liquid Composites Moulding Processes," by A. Endruweit, 2003.

Fabric drape which including the shearing, straightening, stretching, slipping can influence permeability. Figure 31 depicts two elliptical flow fronts related to two satin weave fabric: perfect, sheared. It is clearly seen that the fabric 
is composed of unsheared fibre tows resulting a homogeneous permeability and porosity distribution. However, sheared fabric due to local higher fiber volume cause almost an inhomogeneous permeability distribution. Consequently, the shape of flow front deviates from an initial ellipse. 


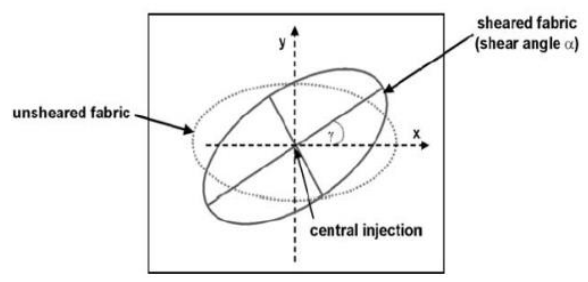

Figure 31. Deviation of flow front due to fabric shearing. Adapted from "Injection Strategies for Liquid Composite Moulding Processes," by G. A. Barandun, 2009.

\section{Mechanical Properties}

A large amount of experimental data demonstrate very strongly that 3D composites improve Mode I and also Mode II interlaminar fracture toughness and decrease macro-delamination in composite. Here we focus on stitched composites and valuable results for other types of preform can be found from (Bogdanovich \& Mohamed, 2009; Horrocks, 2000; Mouritz, 1997; Poe, 1997). Mostly, two main aspects of stitching composite cause research questions: manufacturing cost and mechanical properties. Here we discuss on mechanical properties and degradation of stitched preforms. Stitching process can improve the interlaminasr properties particularly in mode 1 loading, fracture toughness and impact damage resistance. To be clearer, Figure 32 depicts the comparison of different notched stitched composite subjected on tensile loading. From aspect of mechanical properties, we can say that since the tensile strength of composite laminate is highly dependent on the angle between fiber direction and loading direction, therefore tailored fiber placement can be very promising technique to optimize the fiber orientation to have intended peak performance and improve composite mechanical properties during product design.

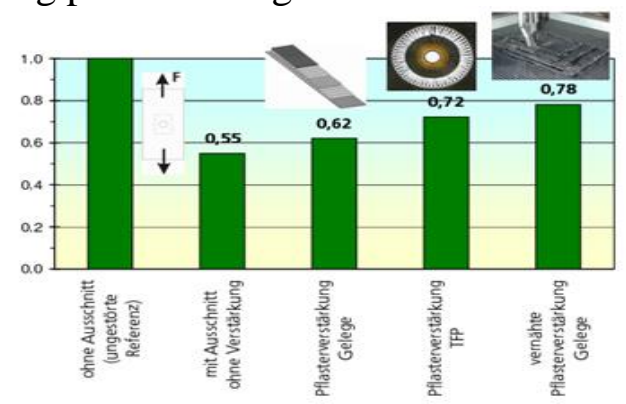

Figure 32. Comparison of strength of laminated and stitched composite. Adapted from "Non-Isothermal Preform Infiltration During the Vacuum-Assisted Resin Transfer Molding (vartm) Process," by M. Grujicic et al., 2005, Applied Surface Science, 245(1-4), pp. 51-64. 
Some experimental results display that stitching process diminishes the stiffness, and fatigue strength of 3D composites around 10-20. Based on literature and technical documents numerous experimental tests have been conducted to realize the amount of the loss in-plane stiffness and strength in different tensile and compression condition, fatigue life and other mechanical properties. Based on literature, stitching technique cannot be fitted to prepreg laminates due to considerable fine damages occurred during stitching process. Regarding dry fabrics, fibre breakages may become source of stress concentration which facilitates the macro damage formation in particular in fatigue loading. To summarize, damage in stitched preforms and subsequent composite failures due to static or dynamic loading are a major concern to their aerospace applications. Therefore, understanding the behaviour of a stitched composite structure subjected to mechanical loadings in particular impacts and hole-edge delaminations due to static or fatigue loads is vital task.

\section{Quality Issues for the Manufacturing of Textile Composite}

The RTM processes can fabricate high performance textile composite structures. Improved resin curing process and control of relevant processing parameters are significant issues to enhance product quality. If these parameters are not controlled, void formation can result the reduction in the mechanical properties (Sickinger \& Herbeck, 2000). The main reasons leading to form void in RTM technique can be classified as follows:

Evaporation of mold: Evaporation of mold in the formation of bubbles in the preform surface leads to macro-voids.

Resin outgassing: Voids can form from the gaseous components coming out of the resin during the vacuum process. Therefore, the resin has to be degassed to reduce the resin outgassing.

Preform permeability: permeability which includes the characteristics of fiber dimensions and arrangement is significant parameters in resin infusion. This parameter allows controlling the fiber impregnation, complete fiber wetting and ensuring high quality textile composite structure. Non-uniform permeability because of preform inhomogeneity causes the resin velocity to change from point to point at micro scale. Differences in permeability result in either bubbles inside fibre bundles, or in the space between fibre bundles (see Figure 33). 


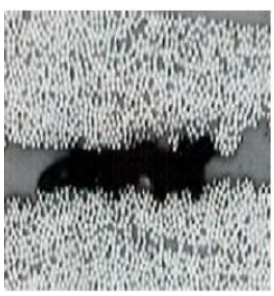

a)

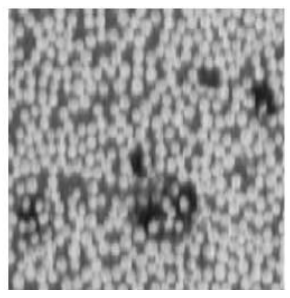

b)

Figure 33. Typical images of void formation textile composite. a) Void in inter fiber bundle; b) Void in intra-fiber bundle. Adapted from "Polymer-Composites: From Nano- to Macro-Scale," by K. F. Friedrich et al., 2005, New York, NY: Springer.

Permeability variations can result in macrovoid and microvoids. Also, void location highly depends upon resin velocity in such a way that high resin velocity will form void within preform tows because the flow in the channel is faster than in the tow (Figure 33a). However, for a low resin velocity, the thin flow will dominate within tows and hence voids may form in the channels between tows (Figure 33b).

Fiber Volume: Increasing the fiber content of composite cause reasonably the decreasing the permeability and voids number. For instance, reduction in void content in composite can be occurred by increasing the fiber volume fraction from $10 \%$ to $40 \%$.

Race tracking: Race tracking occurs when the resin races around the edges of the mold. Race tracking causes large voids of dry fibers in the center of the mold. Race tracking is difficult to avoid as it requires a perfect set up. However, it can be minimized by using a high viscosity resin (Hamidi \& Altan, 2009).

During the infusion process, the preform is submitted to a non-uniform pressure distribution at the inlet and vacuum port. The compaction and the permeability of the resin saturated regions changes with position and flow front progression. Therefore, the thickness of the impregnated part is not uniform; the preform is typically thicker at the inlet where the pressure level is higher.

The relationship between volumetric flow rate and fill pressure is an important design parameter, which is in most cases described by a flow through porous media model given by Darcy's law.

3D Textile campsites offer a highlight weight potential and strength for innovative applications such as modern aircraft. These composites must be inspected accurately due to requirements of safety and reliability. Inspection of textile preforms needs to have sufficient knowledge about the various types of defects in textile preforms and textile composites. One of the major challenges in 3D textile composites for advanced applications is the verification of the manufacturing quality for $3 \mathrm{D}$ textile preforms which have large influence on the 
mechanical properties of the final composite product. This section provides a description of possible defects in textile preforms and composites and then state of the art non-destructive testing techniques to detect damages in preforms and composite will be discussed later.

\section{Defects in composites}

Most common defects appear in textile composite structure are: delamination, ply misalignment, disbands, voids, impact damage, porosity, inclusions, erosion, matrix cracking, inaccurate fibre volume fraction, fiber breakage, kissing bonds, and incorrect cure. Figure 34 exhibits example microscopic images of these defects. To better understanding these defects, a description for each defect is providing as follows:

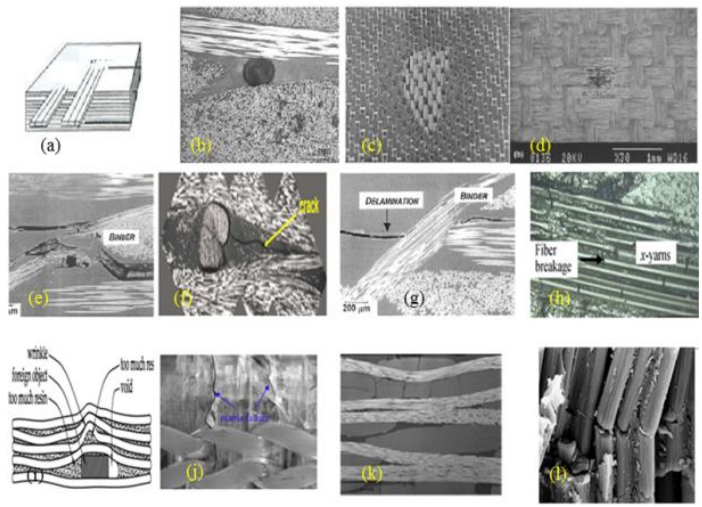

Figure 34. Example image of major defects in textile composite a) edge damage occurred in machining process; b) void between fiber bundle; c) dry path; d) Micrometroid damage; e) Brocken Z-binder; f) micro-crack in the stitched composite; g) delamination in woven composite; h) fiber breakage; i) foreign object; j\&k) matrix crack. Adapted from "Three-Dimensional Reinforcements for Composites," by E. Bogdanovich and M. Mohamed, 2009, and "3D Woven Textiles for Composite Applications, by S. Clarke, 2018.

Fiber Volume Fraction: strength of composites is determined largely by the interaction between the fiber and the matrix. In composite, the load is distributed by matrix between the fibers, therefore, it is significant to know the volume fraction.

Porosity: During manufacturing process and impregnating with resin, small amount of air remains trapped and forms interlaminar voids or porosity.

Inclusion: In the fabrication process of composites foreign materials such as dirt and debris are inadvertently left in composite. These inclusions 
contaminate the matrix or act as a local stress concentration and lead to delamination during the manufacturing process when the composite is in service.

Delamination: Delamination involving fiber breakage and matrix cracking is caused due to impact, overloading or fatigue. Delamination has significant adverse influence on the mechanical performance of the composite structure (see Figure 34e).

Fiber breakage: The compression failure in composite in particular in unidirectional composite occurs due to internal instability mechanism. Fiber buckling due to constraints of the surrounding matrix causes the fiber to break at two points designated kink band. Fiber breakages are mostly proceeded by debonding and matrix micro-cracking damages.

Matrix cracking: Residual stress occurred in manufacturing process can cause microcarck in matrix and debonding damages. Detecting matrix cracks and fiber breakage damages are very difficult, because usually these defects are perpendicular to the composite surface.

Machining damage: To obtain composite with high quality, water jet machine, laser cutting or a thin mill tool on CNC machine with careful feed and speed have to used to cut composite structures to prevent edge damages (see Figure 35).

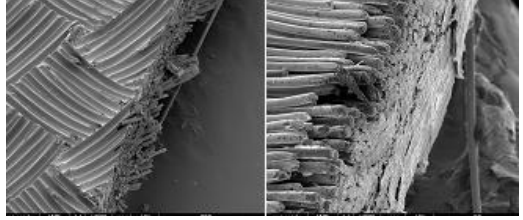

a) b)

Figure 35. Comparison of cutting by (a) laser and (b) mechanical machining. Adapted from "Automated Manufacturing Environment to Address Bulk Permeability Variations and Race-Tracking in Resin Transfer Molding by Redirecting Flow with Auxiliary Gates," by J. M. Lawrence, 2005, Composites Part A: Applied Science and Manufacturing, 36(8), pp. 1128-114.

\section{Damages in 3D textile preforms}

The most important part for the manufacturing 3D textile composites is textile preforms which have considerable influence on the mechanical properties of the textile composite. The various types of defects in textile preforms (2D and 3D) shown in Figure 36 is illustrated below and then the state-of-the-art nondestructive testing to detect these damages found in the literature will be discussed on the next section. 


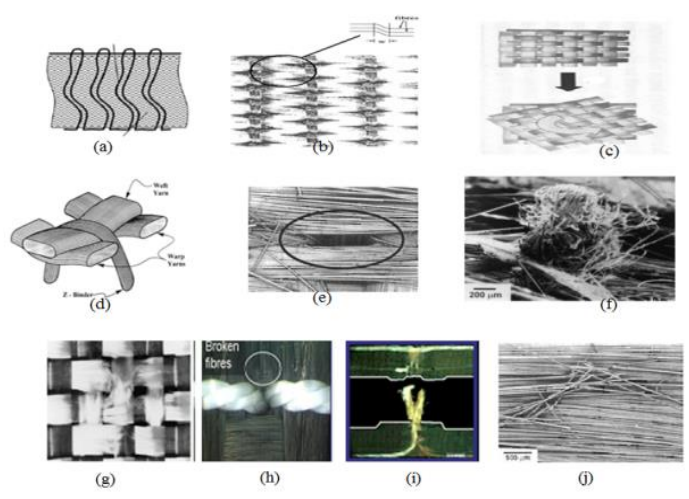

Figure 36. Different types of preform defects. a) misaligned through the thickness yarn; b) Misalignment of fiber bundle due to stitching; c) textile fabric misalignment; d) Fiber crimping; e) Resin rich region; f) Fiber pullout; g-j) fiber breakage. Adapted from "Polymer-Composites: From Nano- to Macro-Scale," by K. F. Friedrich et al., 2005, New York, NY: Springer.

Fiber misalignment: The exact position and orientation of the textile layers have a great effect on composite mechanical characteristics and it can considerably change the performance of final composite. Fiber misalignment in stitched preform is dependent on the diameter of the stitching yarn, the needle diameter, the stitching pattern and the thread tension, for instance, the distance between yarns smaller; therefore, more fiber deviations.

Fiber crimping: Crimping appears by the high shear stress and strain due to the local bending effect of the fibers at the surface of the preform resulting loss of properties. This defect schematically is shown in Figure 36d. The amount of fiber crimping depends on the tension applied on stitching yarn. Also, the amount of crimping in 3D preforms varies due to differences in weave architecture and manufacturing process.

Fiber breakage: This defect occurs because of some problem in preforms manufacturing process. For example, in the stitching process, as the needle penetrates the fabric it can cause localized in-plane fiber damage and fabric distortion, which reduces the mechanical performance of the composite. Fiber breakages in stitched preforms depend on the stitch thread diameter and stitching tension and fabric density.

Resin-rich pocket: The fiber crimping and misalignment results small regions with low fiber content around the stitch thread (Figure 36e).

Compaction: This defect occurs when high tensile load is applied to the stitch thread to ensure that it is enough tough during the compacting the preform plies. Consequently, consolidated stitched composites have the fiber volume fractions more several percent higher than expected. 
Stitch distortions: Heavy compaction of preform occurred in liquid molding, hot pressing or autoclaving techniques can distort the stitching patterns and threads.

Fiber Poll out: The stitching thread may be damaged during stitching process due to twisting, bending, looping action and sliding as the thread passes through the stitching machine.

Inclusions: The preforms may contain impurities in form of chemicals or small objects which can harm fiber strength. Small objects are likely to be trapped in preform to form a void and serve as a potential deboned. In case of sharp-edged inclusions, fibers may be severely damaged upon infiltration.

Moisture entrapment: Textile Preforms may accumulate the moisture if exposed to humidity for an extended period. Therefore, it is necessary to keep preforms under controlled moisture environment and temperatures. Preforms composed of a stack of 2D fabric layers to form a 3D preform structure using stitching should be inspected before stacking. Most common defects in the textile layers are as follows: Kinked or wavy bundles, Brocken fibers, Inclusions/Impurity, Fabric wrinkles, Sheared fabric, Free edges damages, Loosed fibers, Fiber gaps, Moisture entrapment, Knots and Slubs, Mispick and Kinky filling.

\section{Non-Destructive Testing of 3D Textile Composite}

Because of advanced applications of textile composite in aircraft structure, there is high need to non-destructive evaluation (NDE) for these composites. Nondestructive testing process for textile composite can be divided into two parts: inspection of preform and final composite.

\section{Preform inspection}

According to literature, all techniques to inspect textile preforms can be classified as visual testing and radioscopic testing techniques. Visual inspection techniques are the most common NDT methods used to inspect preforms. These techniques are used to inspect visually for the surface defects such as surface breaking, fiber pull out, etc.

In recent years, Laser scanning method has been used to the inspection of preform surface on the basis of triangulation principle. This system (see Figure 37) can inspect the surface defects with a combination a camera for image processing and an integrated laser light section sensor (Unnpórsson, Jonsson, \& Runarsson, 2004). This system can improve the quality of final product and measure and evaluate deviations in the fiber orientation. This machine can carry out the automatic recognition of the textile architecture, measuring the product quality considering the deformation caused by the 3D form. 


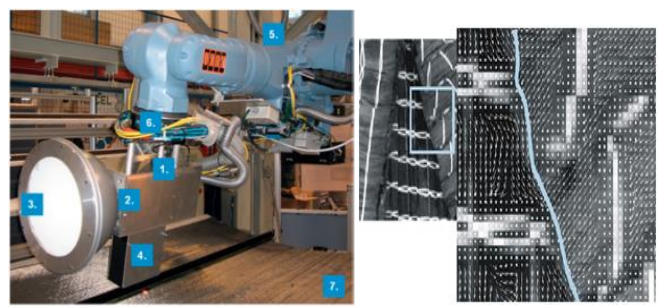

Figure 37. a) Image of laser sectioning machine; b) Example image of fiber orientation detection using laser sectioning system. Adapted from "Recent Advancements in Mechanical Characterisation of 3D Woven Composites," by M. N. Saleh and C. Soutis, 2017, Journal of Mechanics of Advanced Materials and Modern Processes, 3, p. 12.

Dimensional Measurement is another significant task which allows reaching higher quality of preform prior to installing it into mould to the resin infusion and consequently increasing the production cost. The dimensional measurement of textile preform involves the 3D acquisition of using appropriate sensor depending on the preform shape and dimension. Today, laser sources are readily available and particularly tailored for many applications in research and industry. Although lasers are much more expensive than conventional light sources, they offer unsurpassed possibilities for optical testing. Laser scanning method can perform distortion analysis for highly accurate large area preform and complex shape and also monitor the surface conditions before and after the stitching. Despite the significant improvements in laser scanner, several factors still limit the purpose such as accuracy, surface reflective properties and scanning time required to the inspection of textile preforms. Thus, further research is needed to solve these difficulties during the preform inspection. Maybe other laser source such as single point-to-point measurements, similar to laser trackers will be applied for this matter (PenWell Corporation, 2108). To sum up, visual inspection cannot detect internal damages in preforms, therefore other methods such as X-ray radiographic have been employed.

\section{Textile composite inspection}

Developments in non-destructive testing of 3D textile composite inspection may be built on the experience gained with common composite, but of the most frequently methods used with common composite, only ultrasonic and radiography are most sensitive to textile composite defects. The following represents our recent literature review on the non-destructive testing techniques used for the inspection of preform and textile composite. These techniques have been considered to detect major defects in textile composite mentioned above which can be performable for large areas and complex shaped composites as well. 


\section{Ultrasonic \& elastic waves.}

The fundamental principle of ultrasonic detection relies on pulses of highfrequency ultrasonic waves are transmitted into composite. These pulses are either transmitted through a specimen or reflected to the transducer by internal damage. The required data is output in the form of a $\mathrm{C}$-scan represent a planar view looking through the top surface of the structure. By using Ultrasonic $\mathrm{C}$-scanning it is possible to detect delaminations and disbonds as well as volumetric defects including voids within the composite structure in partciluatre complex shapes composites as shown in Figure 38.

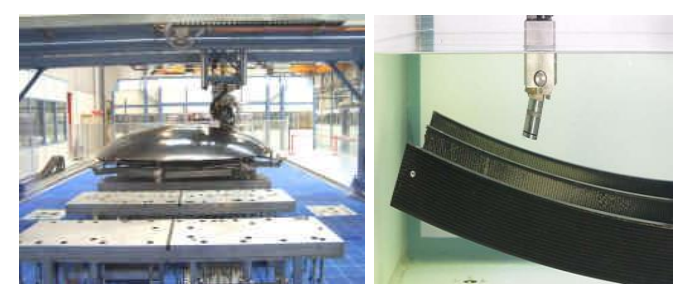

Figure 38. Example of C-scan ultrasonic application to inspect the aircraft pressure bulkhead made by stitched fabrics and braided composite (right). Adapted from "Automated Manufacturing Environment to Address Bulk Permeability Variations and Race-Tracking in Resin Transfer Molding by Redirecting Flow with Auxiliary Gates," by J. M. Lawrence, 2005, Composites Part A: Applied Science and Manufacturing, 36(8), pp. 1128-114.

\section{X-ray techniques.}

$\mathrm{X}$-radiography is a common technique used to detect damages in preforms and composite and only requires an X-ray source and photographic X-ray film to obtain a radiograph. This system produces an image that is a two-dimensional image of the specimen. X-radiography can be applied to the detection of voids in composites, but only when they exhibit absorption of $2 \%$ or more different from the surrounding material. Defects that do not have appreciable depth in the direction of the beam cannot be detected by conventional radiography. For similar reasons, it is very difficult to detect delaminations and cracks perpendicular to the beam using conventional radiography. Also, the detection of fiber volume fraction variations in CFRP composites using with conventional radiography is difficulty, because the matrix and the reinforcement fibres have high content of carbon and similar radiation absorption.

X-rays for the Non-destructive applications are generated during acceleration of electrons in a vacuum while are focused on a target material (tungsten), and forced to interact with it. Such interaction results in the release of photons, which are capable of penetrating solid matter. This ability to penetrate 
matter is related to the extremely short wavelength of electromagnetic radiation of $\mathrm{x}$-rays, which is in the range from $10^{-6}$ to $10^{-10} \mathrm{~cm}$. The applied voltage, typically expressed in kilovolts $(\mathrm{kV})$ is the main governing factor for energy of the radiation. Most commercially applied units operate in the range of 100 to $400 \mathrm{kV}$. Figure 39a shows views of conventional x-ray developed for non-destructive testing of woven composites.

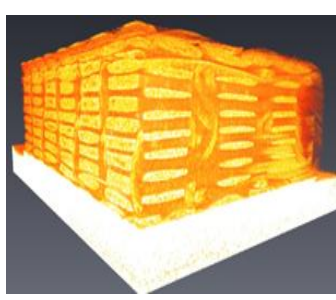

a)

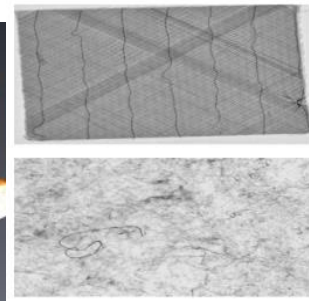

b)

Figure 39. a) conventional X-ray developed for the inspection woven composite; b) X-ray image of two different fabrics. Adapted from "A Method for Edge Detection of Textile Preforms Using a Light-Section Sensor for the Automated Manufacturing of Fibre-Reinforced Plastics," by R. Schmitt, 2007; "Testing Process Monitoring: Looking Right Into the Texture," by A. Miene A, 2009, Kunststoffe International, 99(5); and "Slashing Inspection Time with Laser rRadar Mv330/350,” by Nikon, 2009.

Digital X-ray tomosynthesis is other X-ray technique have been used for producing slice images using conventional $\mathrm{X}$-ray systems. This technique can be employed to the determination of the fiber distribution in the sewing process and identification of the orientation of the preform (Blomme, Bulcaen, Declercq, \& Lust, 2003). As shown in Figure 40a, the X-ray tube and the detector move in a correlated way to generate several slices out of one measurement by simple geometrical reflections. The disadvantage of this technique is low contrast and weak image quality due to the smearing remains (Hassler, Schloetzer, \& Hanke, 2007). 


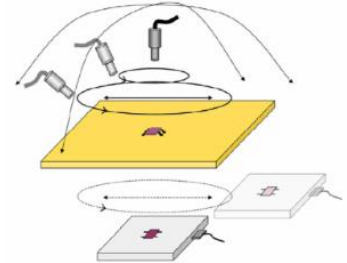

a)

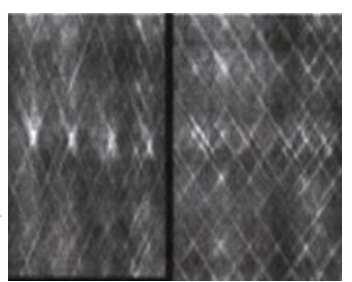

b)

Figure 40. a) tomosynthesis setup; b) X-ray images of a preform. Adapted from "Porosity Measurement Service Using X-Ray Tomography," by P. Hermanek and S. Carmignato, 2017, Precision Engineering, 49, pp. 377-387.

$\mathrm{X}$-Ray micro tomography as promising NDT techniques focuses the X-ray beam to 10-micron spot sizes and a series of typically 360 to 720 radiographs. This radiograph images are taken by rotating the object about one axis (see Figure 41). The resulting data is reconstructed in software to produce a $3 \mathrm{D}$ image of the component that can be viewed through any image plane. Micro tomography could create cross-sections of a 3D preforms that can be used to recreate a virtual model without destroying or disrupting the original preform. This technique is a reliable technique to quantify the internal geometry and the variability of a 3D textile preform and composite such as the yarn width and thickness and spacing between the fiber bundles. However, X-ray imaging at these smaller scales can introduce challenges.

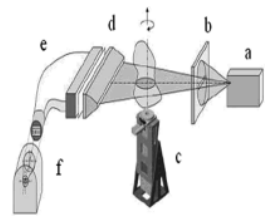

a)

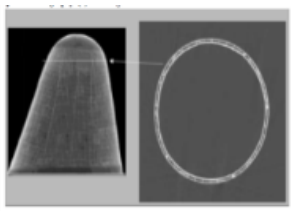

b)

Figure 41. a) Micro-tomography images of the stitched composites prepared by micro-CT method; b) 3D Micro CT image of 3D preforms. Adapted from "Carbon Fibre Preform Inspection by Circular X-Ray Tomosynthesis," by U. Hessler, 2008; "Non Destructive Testing of Composite Materials," by A. Kapadia, 2007; and "Computed Tomography for Analysis of Fiber Distribution in Carbon Fiber Preform," by U. Hassler and R. Hanke, 2007.

\section{Conclusions}

The review paper has covered 3D textile preforms and composite specifications and various types of damages in these materials. Furthermore, the review concentrated on deformation mode of textile fabrics, fabric architects and 
their specific specification in particular stitched preforms. It seems that currently the size of the stitched composite structures is limited by the size of stitching machine. A large amount of experimental data has been published on the strength of stitched composites for various load conditions, but there is still an impediment to the acceptance of stitched textile fabrics for aerospace composites industry due to uncertainty and conflicting research results concerning their degradation and in plane properties. This is probably because of not disclosing the key parameters such as thread tension, needle size etc. Furthermore, the state-of-the art nondestructive testing (NDT) techniques developed for detecting defects in 3D preforms and composite was presented. At the moment, it can be claimed that Xray imaging method especially micro $\mathrm{CT}$ technique and $\mathrm{C}$-scan ultrasonic are most useful methods to detect damages in textile preform and composite. 


\section{References}

Aeronautics research. (n.d.). Retrevied from http://www.aeronautics.nasa.gov

Aroush, D., Gauthier, C., Youssef, S., \& Wagner D. (2006). A study of fracture of unidirectional composites using in situ high-resolution synchrotron X-ray microtomography. Composites Science \& Technology, 66, 1348-1353.

Baillargeon, Y., \& Vu-Khanh, T. (2001). Prediction of fiber orientation and microstructure of woven fabric composites after forming. Composite Structures, 52(3-4), 475-481.

Baoxing, C., \& Tsu-Wei, C. (2000). Compaction of woven-fabric preforms: Nesting and multi-layer deformation. Composites Science And Technology, 60(12), 2223-2231.

Barandun, G. A. (2009). Injection strategies for liquid composite moulding processes. doi: https://doi.org/10.3929/ethz-a-005963299

Bissell. (n.d.). Knowledge center. Retrieved from http://www.beisselneedles.com

Blomme E., Bulcaen, D., Declercq, F., \& Lust, P. (2003). Air-coupled ultrasonic detection of errors in textile products. Retreived from http://www.conforg.fr/wcu2003/procs/cd1/articles/000135.pdf

Bogdanovich, E., \& Mohamed M. (2009, Nov/Dec). Three-dimensional reinforcements for composites. Proceedings of the ICCM International Conferences on Composite Materials, Edinburgh, UK.

Clarke, S. (2018). 3D woven textiles for composite applications. Retrieved from http://www.uammi.org/new/wp-content/uploads/2018/03/06-Steve-ClarkeTEAM-3D-Weaving-UAMMI-Slides-032018.pdf

Cyber and digital resilience. (n.d.). Retreived from http://www.qinetiq.com

Djukic L. (2009). Contrast enhancement in visualisation of woven composite architecture using a microct scanner. Part 2: Tow and preform coatings. Composites Part A: Applied Science And Manufacturing, 1870-1879.

Endruweit A. (2003). Investigation of the influence of local inhomogeneities in the textile permeability on the resin flow in liquid composites moulding processes. Retreived from https://www.research-collection.ethz.ch/ handle/20.500.11850/45751

Ermanni P. (2009). Textile halbzeuge. Retreived from https://www.carbonconnected.de/ Group/ ETH.Zuerich.Institut.fuer.Mechanische. Systeme.Zentrum.fuer.Strukturtechnologien/

Friedrich, K. F., Fakriov, K., \& Zhong, Z. (Eds.). (2005). Polymer-composites: From nano- to macro-scale. Retrieved from http://acwc.sdp.sirsi.net/ client/en_US/default/search/detailnonmodal/ent:\$002f\$002fSD_ILS\$002f 186\$002fSD_ILS: $186168 / \mathrm{ada} /$ ?qu=Thermoplastic+composites+-+Testing.doi: 10.1007/b137162

Gardner Business. (n.d.). Integrated, optimized aircraft door - high performance composites. Retreived from www.compositesworld.com 
Grujicic M., Chittajallu, K. M., \& Walsh S. (2005). Non-isothermal preform infiltration during the vacuum-assisted resin transfer molding (vartm) process. Applied Surface Science, 245(1-4), 51-64.

Hamidi Y. K., \& Altan C. (2009). Effect of fiber content on void morphology in resin transfer molded e-glass/epoxy composites. Engineering Materials And Technology, 131(2), 2009.

Hassler U., \& Hanke R. (2007). Computed tomography for analysis of fiber distribution in carbon fiber preforms. Paper presented at the International Symposium On Digital Industrial Radiology And Computed Tomography, Lyon, France.

Hassler U., Schloetzer, S., \& Hanke, R. (2007). Computed tomography for analysis of fiber distribution in carbon fiber preforms. Paper presetned to the International Symposium on Digital industrial Radiology and Computed Tomography, June 25-27, 2007, Lyon, France. Retreived from https://www.ndt.net/ article/dir2007/ papers/28.pdf

Hearle, J. (2015). Introduction. In X. Chen, Advances in 3D textiles. Cambridge, England: Woodhead.

Hermanek, P., \& Carmignato, S. (2017). Porosity measurement service using Xray tomography. Precision Engineering, 49, 377-387.

Hessler U. (2008). Carbon fibre preform inspection by circular $x$-ray tomosynthesis. Paper rpesented at the IEEE Nuclear Science Symposium Conference 2008, Dresden, Germany, 590 - 592.

Horrocks, A. R., (2000). Handbook of technical textiles. Cambridge, England: Woodhead.

Interempresas.net. (n.d.). Informacion. Retreived from http://www.interempresas.net/Informacion

Kapadia A. (2007). Non destructive testing of composite materials. Natural Composties Network.

KU Leuven. (2018). Research. Retreived from https://www.kuleuven.be/ onderzoek/

Lawrence J. M. (2005). Automated manufacturing environment to address bulk permeability variations and race-tracking in resin transfer molding by redirecting flow with auxiliary gates. Composites Part A: Applied Science and Manufacturing, 36(8), 1128-114.

Lomov S., Boisse, P., Deluycker, E., \& Moresten, F. (2008). Full-field strain measurements in textile deformability studies. Composites Part A: Applied Science And Manufacturing, 39(8), 1232-1244. doi:10.1016/j.compositesa.2007.09.014

Long, A. C. (2009). Design and manufacture of textile composites. Boca Raton, FL: CRC. 
Louis, M., \& Huber, U. (2003). Investigation of shearing effects on the permeability of woven fabrics and implementation into $1 \mathrm{~cm}$ simulation. Composites Science And Technology, 63(14), 2081-2088.

Luycker E. (2006). Simulation of $3 d$ interlock composite preforming. Composite Structures, 88(4), 615-623, 2005.

Mazumdar S. (2002). Composites manufacturing: Materials, product and process engineering. Boca Raton, FL: CRC.

Meier R., Walbran A., Hahn C., Zaremba, S., \& Drechsler, K. (2014). Methods to determine the permeability of textile reinforcements. Zeitschrift Kunststofftechnik/Journal of Plastics Technology, 10(4), 90-116.

Miene, A. (2009). Testing - process monitoring: Looking right into the texture. Kunststoffe International, 99(5).

Mitschang P., \& Ogale, A. (2009). Quality aspects of and thread selection for stitched preforms. Retreived from http://www.iccm-central.org/ Proceedings/ ICCM17proceedings/Themes/ Manufacturing /MANUFACTURING\%20TECH/C3.4\%20Mitschang.pdf

Mountasir, A., Löser, M., Hoffmann, G., Cherif, C., \& Großmann, K. (2016). 3D woven near-net-shape preforms for composite structures. Advanced Engineering Materials, 18(3), 391-396.

Mouritz, A. (1997). Review of applications for advanced three-dimensional fibre textile composites. Compsoite, 30(12), 1445- 1461.

Naouar N., Vidal-Salle, E., Schneider, J., Maire, E., \& Boisse P. (2015). 3D composite reinforcement meso FE analyses based on X-ray computed tomography. Journal of Composite Structures, 132, 1094-1104.

Neitzel, M. (2004). Handbuch Verbundwerkstoffe. Munich, Germany: Nanzer.

Nikon. (2009). Slashing inspection time with laser radar Mv330/350. Retreived from www.nikonmetrology.com

Ogale, A., \& Mitschang P. (2004). Tailoring of textile preforms for fibre reinforced polymer. Composites, 34(2), 77-96.

Otluri, P., \& Atkinson, J. (2003). Automated manufacture of composites: Handling, measurement of properties and lay-up simulations. Composites Part A: Applied Science And Manufacturing, 34(6), 493-501.

PenWell Corporation. (2108). Indutrial laser solutions. Retreived from https://www.industrial-lasers.com/index.html

Poe, C. (1997). A review of the NASA textile composites research, T.R.N. -971321. Washington, DC: National Aeronaurces and Space Administation.

Potluri P., \& Sagar, T. V. (2008). Compaction modelling of textile preforms for composite structures. Composite Structures, 86(1-3), 177-185.

Potluri A., Sharif, T., \& Jetavat, D. (2008). Robotic approach to textile preforming for composites. Indian Journal Of Fibre \& Textile Research, $31,333-338$. 
Robitaille, F., \& Gauvin, R. (2014). Compaction of textile reinforcements for composites manufacturing. I: Review of experimental results. Polymer Composites, 19(2), 198-216. https://doi.org/10.1002/pc.10091

Robo-technology.com (n.d.). Design. Retreived from http://www.robotechnology.com/robo/de/kompetenzen/maschinenbau

Saleh, M. N., \& Soutis, C. (2017). Recent advancements in mechanical characterisation of 3D woven composites. Journal of Mechanics of Advanced Materials and Modern Processes, 3, 12. https://doi.org/10.1186/s40759-017-0027-z

Schmitt R. (2007). A method for edge detection of textile preforms using a lightsection sensor for the automated manufacturing of fibre-reinforced plastics. Proceedings Of Spie Optical Measurement Systems For Industrial Inspection V At The World Of Photonics Congress, Munich, Germany.

Sickinger C., \& Herbeck L. (2000). Eine maßnahme zur realisierung von hochleistungsfaserverbundstrukturen. Retreived from https://www.dlr.de/fa/ Portaldata/17/Resources/ dokumente/institut/ 2000/2000_03.pdf

Simacek P., Advani, S. G., \& Iobst, S. A. (2008). Modeling flow in compression resin transfer molding for manufacturing of complex lightweight highperformance automotive parts. Journal of Composite Matererails 42(23), 2523-2545.

Sozer, E. M., Chen, B., Graham, P. J., Chou, T. W., \& Advani, S. G. (1999). Characterization and prediction of compaction force and preform permeability of woven fabrics during the resin transfer molding process. Retreived from https://www.fose1.plymouth.ac.uk/sme/ fpcm/fpcm05/ FPCM5_Sozer2.pdf

Tong L., Mouritz, A. P., \& Bannist, M. (2002). 3D fibre reinforced polymer composites. London: Elsevier Science.

Unnpórsson R., Jonsson, M. T., \& Runarsson, T. P. (2004). Ndt methods for evaluating carbon fiber composites. Retreived from https://notendur.hi.is/runson/ Project/ comptest2004_paper.pdf

Uozumi, T., Kito, A., \& Yamamoto, T. (2005). Cfrp using braided preforms/rtm process for aircraft applications. Advanced Composite Materials, 14(4), 365-383.

Vernet, N., \& Trochu F. (2015). In-plane and through-thickness permeability models for three dimensional Interlock fabrics. Journal of Composite Materials, 50(14), 1951-69.

Weimer C., Mitschang P., \& Drechsler K. (2000). Approach to net-shape preforming using textile technologies. Part I: Edges. Composites: Part A, 31(11), 1261-1268. 
International Journal of Aviation, Aeronautics, and Aerospace, Vol. 6 [2019], Iss. 1, Art. 2

https://commons.erau.edu/ijaaa/vol6/iss1/2 